\title{
Investigation of the thermal behavior of 4-vinylpyridine-trimethylolpropane trimethacrylate copolymeric microspheres
}

\author{
Marta Grochowicz
}

Received: 2 June 2014/ Accepted: 3 August 2014/Published online: 29 August 2014

(c) The Author(s) 2014. This article is published with open access at Springerlink.com

\begin{abstract}
The study describes the thermal properties of porous microspheres synthesized with functional monomer 4-vinylpyridine (4VP) and crosslinking agent trimethylolpropane trimethacrylate (TRIM). Polymeric 4VP-TRIM microspheres were prepared via seed polymerization, using polystyrene microbeads as a shape template. The resulting 4VP-TRIM microspheres were in the range of 9-12 $\mu \mathrm{m}$, with specific surface area of about $200 \mathrm{~m}^{2} \mathrm{~g}^{-1}$. The thermal properties of 4VP-TRIM materials were evaluated by thermogravimetry and differential scanning calorimetry. By TG/FTIR/MS, it was observed that new porous materials exhibited multi-staged decomposition patterns, different from poly(TRIM) microspheres. DSC and TG experiments showed that water molecules were absorbed on the materials' surface. The synthesized 4VP-TRIM microspheres exhibited rather high thermal stability. Their initial decomposition temperature was about $300{ }^{\circ} \mathrm{C}$. During the microspheres' decomposition, an evolution of carbon dioxide, water, and carbon monoxide as main gases, as well as of pyridine and aliphatic compounds, was observed. It was confirmed that the evolved pyridine accelerated the degradation of copolymeric network.
\end{abstract}

Keywords Polymeric porous microspheres . 4-Vinylpyridine - Thermal stability - Thermogravimetric analysis $\cdot$ TG/FTIR/MS

M. Grochowicz $(\square)$

Department of Polymer Chemistry, Faculty of Chemistry, Maria Curie Skłodowska University, Gliniana 33, 20-614 Lublin, Poland

e-mail: mgrochowicz@umcs.pl

\section{Introduction}

Nowadays polymer particles have many areas of applications such as separation, chromatography, adsorbents, ion exchangers, drug-delivery systems, or solid-phase peptide synthesis. Each application requires customized properties in the particles. Taking into account, the utilization of polymeric microspheres in the field of chromatography, control of the particle size, the size distribution, the polymer composition, porosity, and functionality should be especially considered. Functionality can be introduced onto the particle surface by applying functional monomers [1-4] that can also play the role of crosslinking agents [5, 6]. A more complicated route of functionalizing the surface of microspheres is the incorporation into the polymer network of a reactive monomer capable of derivatization, e.g., epoxide rings or chloroalkyl moiety $[7,8]$. The porous structure of polymeric microspheres is formed during the polymerization process and is connected with the phase separation mechanism. Depending on the type of pore-forming diluents and the amount of the crosslinker, macroporous polymer networks with micro-, meso-, and macropores can be produced. Appropriate selection of poreforming diluents allows obtaining microspheres with tailormade morphological properties. The size of polymeric microspheres and their size distribution are related to the polymerization method. Uniform crosslinked polymeric microspheres with narrow size distribution and the size range of $5-20 \mu \mathrm{m}$ can be prepared by several multistage methods: activated swelling procedure, seeded emulsion polymerization, staged shape template polymerization, or two-stage precipitation polymerization [9-11]. In each of the mentioned methods, the start polymer particles with narrow size distribution are needed. In most cases reported in the literature, polystyrene particles are used, but poly(methyl methacrylate) or poly(glycidyl methacrylate) microbeads can also be 

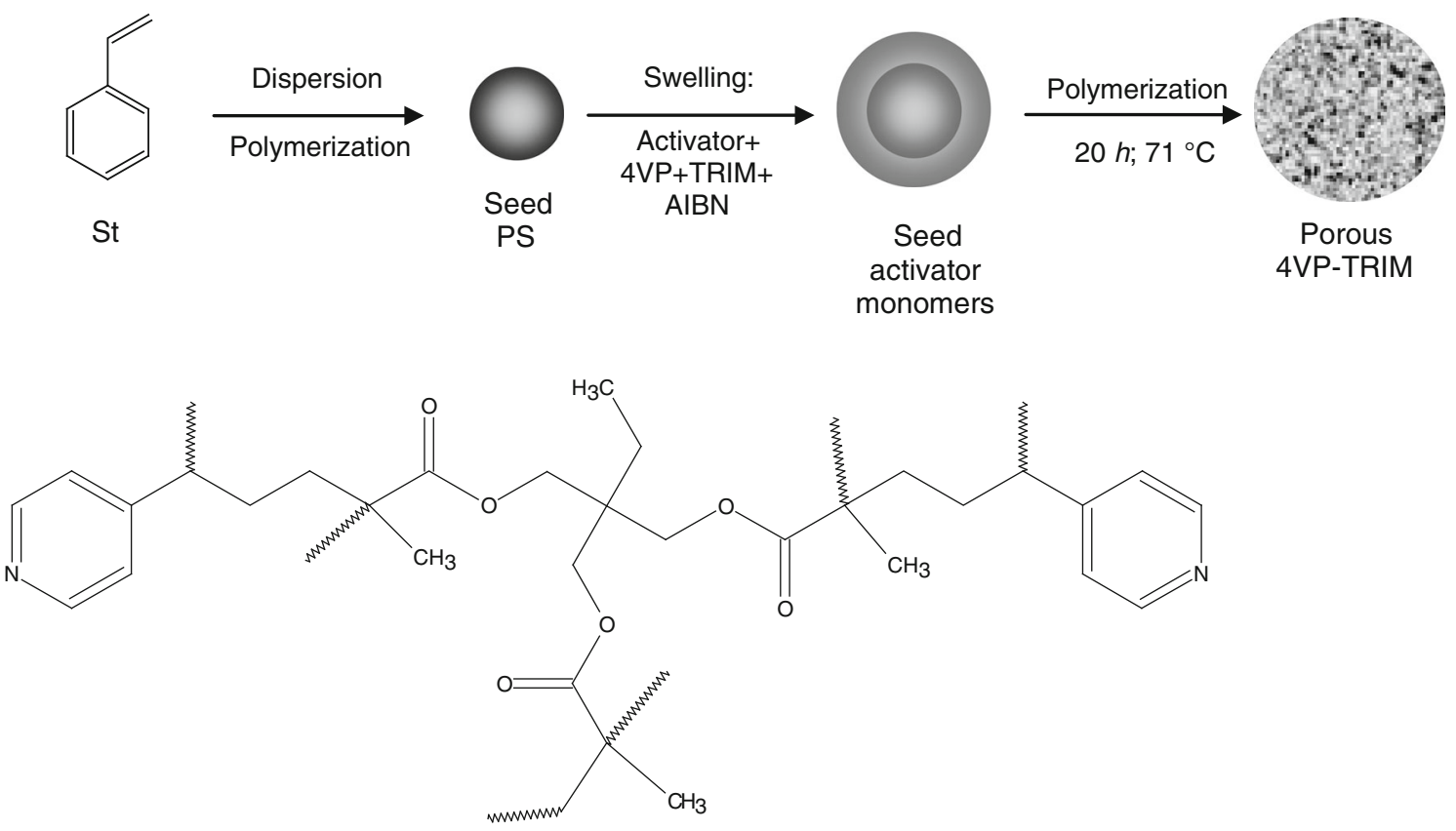

Fig. 1 The scheme of microspheres synthesis and the fragment of copolymer chemical structure

applied. These start particles are obtained preferably by dispersion polymerization and act not only as a shape template, but are also responsible for creating the pore structure in the final microspheres. Until now, considerable research effort has been focused on the synthesis of monodisperse polymeric microspheres with a less hydrophobic nature than poly(styrene-divinylbenzene).

In many cases, the use of polymeric microspheres as catalysts, solid-phase synthesis supports, and also adsorbents is limited by their thermal stability. The thermal resistance of adsorbents used in chromatographic methods, such as poly(styrene-divinylbenzene), polyacrylic acid, acrylicdivinylbenzene copolymers, and dendrimeric materials was reported in literature [12-15]. In our studies, we intended to obtain porous microspheres of 4-vinylpyridine crosslinked with trimethylolpropane trimethacrylate. Polymeric 4VPTRIM microspheres were prepared via seed polymerization, using polystyrene microbeads as a shape template. The aim of this work was an investigation of the thermal properties of 4VP-TRIM polymeric microspheres prepared by seed polymerization, using differential scanning calorimetry (DSC) and thermogravimetry coupled with FTIR and QMS to analyze the evolved products during their decomposition.

\section{Experimental}

\section{Materials}

Styrene, 4-vinylpyridine, trimethylolpropane trimethacrylate (TRIM) and $\alpha, \alpha^{\prime}$-azoisobisbutyronitrile (AIBN), and sodium lauryl sulfate (SDS) were obtained from SigmaAldrich Chemie (Steinheim, Germany). Toluene, methanol, ethanol, tetrahydrofuran, and acetone were from $\mathrm{POCh}$ (Gliwice, Poland).

Preparation porous microspheres

Microspheres of 4-vinylpyridine (4VP) crosslinked with trimethylpropane trimethacrylate (TRIM) were obtained by seeded polymerization. Molar ratio of 4VP to TRIM was in the range of (0.5-2):1; toluene was used as an activator. As the start polymer, polystyrene microspheres (PS) were used. Dispersion polymerization was chosen as a suitable method for making PS particles with $M w=19,500 \mathrm{Da}$. Polymerization was carried out at $71{ }^{\circ} \mathrm{C}$ during $20 \mathrm{~h}$. After the reaction was completed, the obtained spheres were extracted with hot THF for $4 \mathrm{~h}$ to remove seed particles. In Fig. 1, the scheme of microspheres preparation and a fragment of the copolymer structure are presented.

\section{Methods of analysis}

Elemental analysis (CHN) was made using a Perkin-Elmer CHN 2450 analyzer (Palo Alto, CA, USA). ATR-FTIR spectra were recorded on a Tensor 27 (Bruker) spectrometer equipped with a diamond crystal. The spectra were recorded in the spectral range of $600-4,000 \mathrm{~cm}^{-1}$ with a resolution of $4 \mathrm{~cm}^{-1}$ and 50 scans.

Thermogravimetric analysis of materials was carried out with a Netzsch STA 449 F1 Jupiter thermal analyzer (Germany) at the heating rate of $10 \mathrm{~K} \mathrm{~min}^{-1}$, in the 


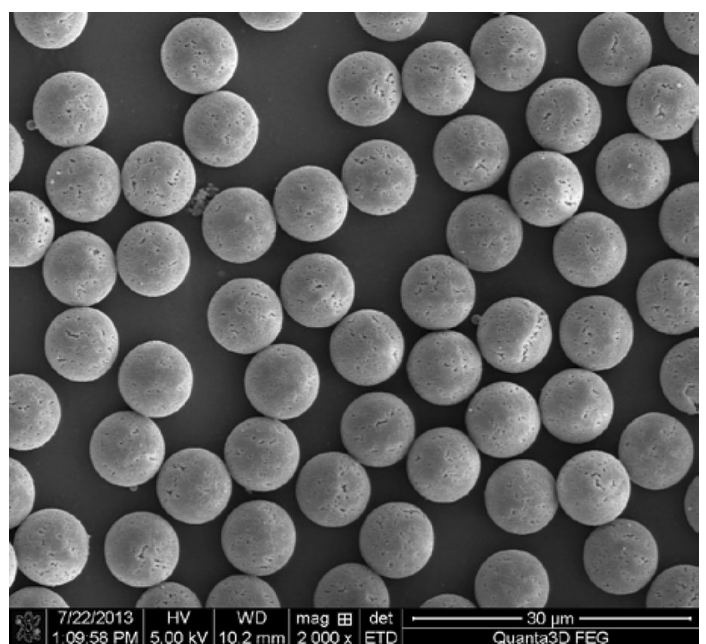

Fig. 2 SEM image of 4VP-TRIM microspheres

temperature range of $20-850{ }^{\circ} \mathrm{C}$, with the sample mass of $10 \mathrm{mg}$ in two atmospheres: helium and synthetic air $(80 \%$ nitrogen, $20 \%$ oxygen). The gas flow was $20 \mathrm{~mL} \mathrm{~min}^{-1}$. The gas composition which evolved during the decomposition process was detected and analyzed by a quadrupole mass spectrometer QMS 403C Aëolos (Germany), as well as an FTIR Tensor 27 Bruker (Germany) spectrometer coupled on-line to a STA instrument. The mass spectrometer was connected on-line to the STA instrument by a quartz capillary heated to $300{ }^{\circ} \mathrm{C}$. The QMS was operated with an electron impact ionizer with the energy of $70 \mathrm{eV}$. The measurements were performed in scan mode for $m / z$, where $m$ is the mass of the molecule and $z$ is the charge of the molecule in electron charge units in the range of 10-100 amu.

Calorimetric measurements were carried out with the Netzsch DSC 204 calorimeter (Germany) operating in the dynamic mode. The dynamic scans were performed at the heating rate of $10 \mathrm{~K} \mathrm{~min}^{-1}$ from room temperature to the maximum of $550{ }^{\circ} \mathrm{C}$ under helium $\left(30 \mathrm{~mL} \mathrm{~min}^{-1}\right)$ and synthetic air $\left(30 \mathrm{~mL} \mathrm{~min}^{-1}\right)$ atmospheres in two stages. The first scan was performed from room temperature to the maximum of $120{ }^{\circ} \mathrm{C}$ to remove any adsorbed moisture, especially water. The second scan was conducted between 20 and $550{ }^{\circ} \mathrm{C}$. The mass of the sample was $10 \mathrm{mg}$. As a reference, an empty aluminum crucible was used.

\section{Results and discussion}

With the use of seed polymerization 4VP-TRIM microspheres with different morphologies and degree of crosslinking were obtained. They have narrow size distribution and diameters about 9-12 $\mu \mathrm{m}$ depending on the seed type. Figure 2 presents the SEM images of 4VP-TRIM microspheres prepared on PS seed. As can be seen, synthesized

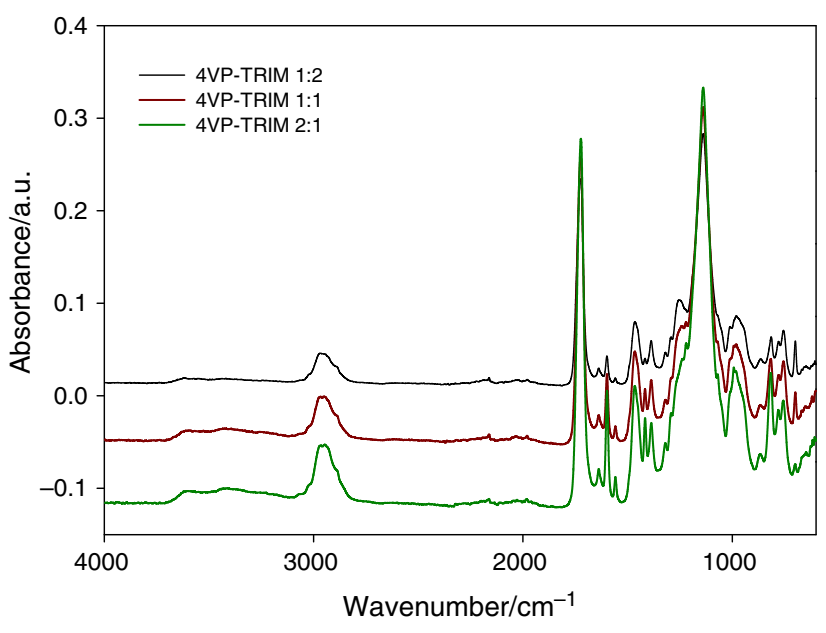

Fig. 3 ATR-FTIR for 4VP-TRIM microspheres

Table 1 CHN, TG, and DTG data for prepared microspheres

\begin{tabular}{lllllll}
\hline Copolymer & $\% \mathrm{~N}$ & $\begin{array}{l}T_{5 \%} / \\
{ }^{\circ} \mathrm{C}\end{array}$ & $\begin{array}{l}T_{50 \%} / \\
{ }^{\circ} \mathrm{C}\end{array}$ & $\begin{array}{l}T_{\max 1} / \\
{ }^{\circ} \mathrm{C}\end{array}$ & $\begin{array}{l}T_{\max 2} / \\
{ }^{\circ} \mathrm{C}\end{array}$ & $\begin{array}{l}T_{\max 3} / \\
{ }^{\circ} \mathrm{C}\end{array}$ \\
\hline $\begin{array}{l}\text { Helium atmosphere } \\
\text { poly(TRIM) }\end{array}$ & - & 279 & 387 & 374 & 437 & 565 \\
4VP-TRIM 1:2 & 1.48 & 303 & 374 & 344 & 384 & 554 \\
4VP-TRIM 1:1 & 2.54 & 320 & 373 & 344 & 380 & 553 \\
4VP-TRIM 2:1 & 3.29 & 311 & 356 & 343 & - & 520 \\
Air atmosphere & & & & & & \\
poly(TRIM) & - & 270 & 376 & 364 & 410 & 560 \\
4VP-TRIM 1:2 & 1.48 & 297 & 325 & 323 & - & 484 \\
4VP-TRIM 1:1 & 2.54 & 299 & 321 & 319 & - & 478 \\
4VP-TRIM 2:1 & 3.29 & 301 & 323 & 319 & - & 478 \\
\hline
\end{tabular}

microspheres are monodisperse with calculated $\mathrm{CV}<10 \%$. The porous structure analysis made by nitrogen adsorptiondesorption method indicated that the prepared materials posses a developed porous structure with specific surface area of about $200 \mathrm{~m}^{2} \mathrm{~g}^{-1}$.

The chemical structure of 4VP-TRIM microspheres was investigated by means of the ATR-FTIR analysis. Figure 3 presents the ATR-FTIR spectra of the materials. In each spectrum bands at 1,466 and $2,930 \mathrm{~cm}^{-1}$ attributed to the $\mathrm{C}-\mathrm{H}$ vibrations in the $-\mathrm{CH}_{3}$ and $-\mathrm{CH}_{2}$ groups are observed. The absorption peak of the carbonyl group is present at $1,725 \mathrm{~cm}^{-1}$, the band at $1,146 \mathrm{~cm}^{-1}$ is attributed to the $\mathrm{C}-\mathrm{O}-\mathrm{C}$ group vibration. The $\mathrm{C}=\mathrm{N}$ stretching and the $\mathrm{C}=\mathrm{C}$ stretching of $4 \mathrm{VP}$ ring occur at 1,599 and $1,558 \mathrm{~cm}^{-1}$, respectively, and peak intensity increases with the increasing amount of $4 \mathrm{VP}$ in the polymeric networks. Moreover, peaks at $1,638 \mathrm{~cm}^{-1}$ presented in each spectrum indicate that unreacted $\mathrm{C}=\mathrm{C}$ double bonds are still present in the prepared materials. In the network of 4VP-TRIM 


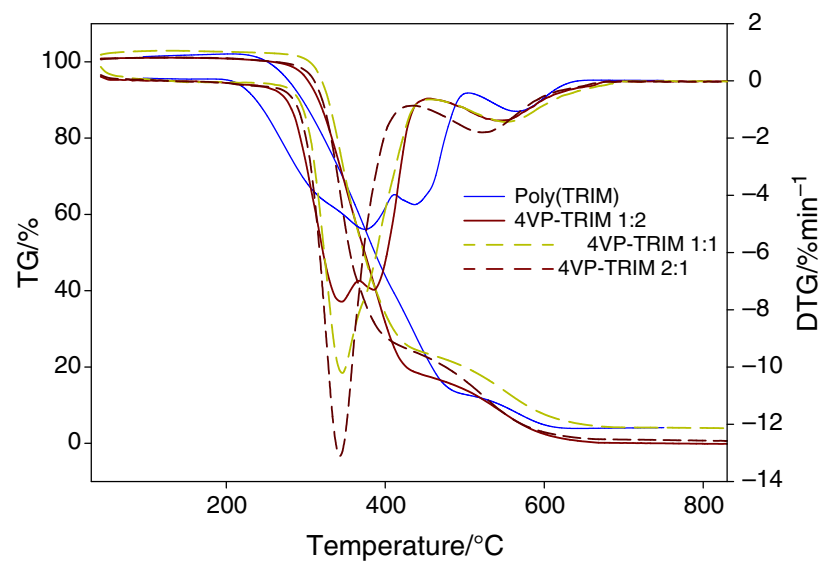

Fig. 4 TG and corresponding DTG curves for poly(TRIM) and 4VPTRIM microspheres obtained in helium atmosphere

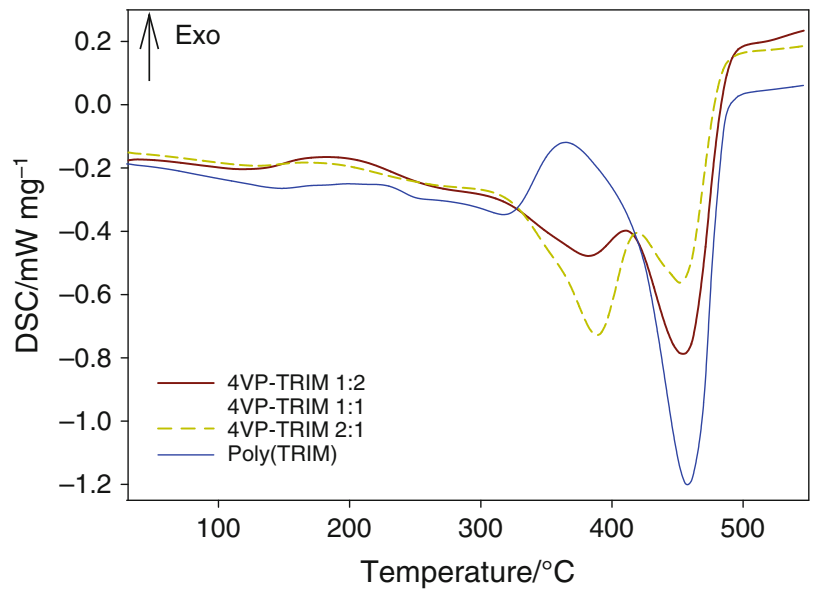

Fig. 5 DSC curves for poly(TRIM) and 4VP-TRIM microspheres obtained in helium atmosphere

$1: 2$, the largest amount of unreacted methacrylate groups remained. The presence of $4 \mathrm{VP}$ in the structure of prepared microspheres was also evidenced by $\mathrm{CHN}$ analysis. As can be seen from Table 1, nitrogen derived from 4VP monomer was detected in each material. Its amount increased with the increasing molar ratio of 4VP to TRIM in the monomer mixture.

The thermal behavior of all samples was investigated by means of thermogravimetry coupled with FTIR and QMS analysis. TG curves for poly(TRIM) and copolymers with $4 \mathrm{VP}$, obtained at the heating rate of $10 \mathrm{~K} \mathrm{~min}^{-1}$ in inert conditions, are presented in Fig. 4. For easier comparison of the samples, DTG curves are also presented in this figure. The temperature of 5 and $50 \%$ of mass loss $\left(T_{5 \%}\right.$, $T_{50 \%}$ ) and the temperature of the maximum rate of mass loss $\left(T_{\max }\right)$ obtained from DTG curves are placed in Table 1. The poly(TRIM) polymer exhibits multistep degradation with three detectable stages in inert atmosphere. The first with a maximum at $378{ }^{\circ} \mathrm{C}$, preceded by a (a)

(b)
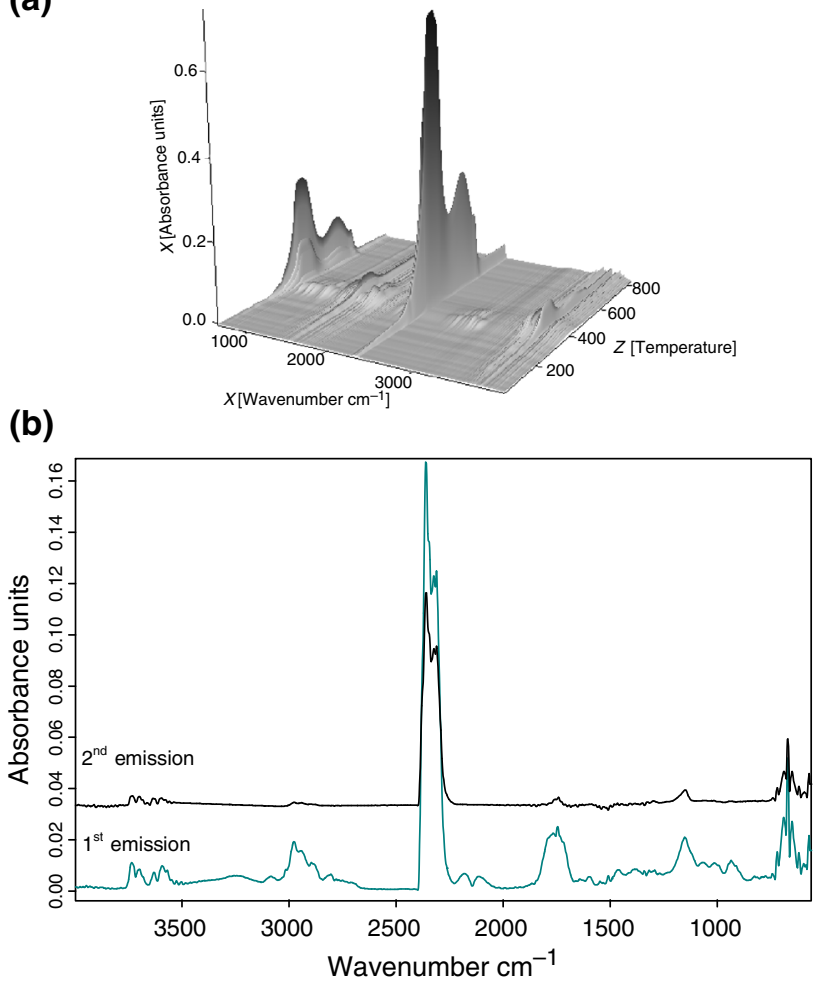

Fig. 6 a 3D diagram of FTIR absorption of evolved gases for 4VPTRIM 1:1 obtained in inert atmosphere. b FTIR spectra of gases evolved from 4VP to TRIM 1:1 at the maxima of decomposition

shoulder at about $300{ }^{\circ} \mathrm{C}$, the second with a maximum at $445{ }^{\circ} \mathrm{C}$, and the third at $566^{\circ} \mathrm{C}$. According to the literature $[16,17]$, the poly (4VP) homopolymer exhibits one sharp degradation step, starting at $\sim 320{ }^{\circ} \mathrm{C}$, with a mass loss of $98 \%$ at $600{ }^{\circ} \mathrm{C}$. The DTG curves for copolymers $4 \mathrm{VP}-$ TRIM reveal a complex degradation process, and the shapes of the curves are changing with the copolymers composition. The material 4VP-TRIM 1:2 with the highest TRIM content exhibits three steps of degradation. The first with onset at ca $278{ }^{\circ} \mathrm{C}$ is followed by the next two with maxima at 383 and $546{ }^{\circ} \mathrm{C}$. The higher amount of $4 \mathrm{VP}$ units in 4VP-TRIM 1:1 copolymer network increases its thermal stability to $303{ }^{\circ} \mathrm{C}$ and also causes the disappearance of the second peak on the DTG curve, only the peak broadening is visible. In the case of the 4VP-TRIM 2:1 material, only a two-stage degradation process is observed. It starts at ca $299{ }^{\circ} \mathrm{C}$. The incorporation of larger amount of $4 \mathrm{VP}$ in the material structure decreases its crosslinking and reduces its thermal stability in comparison with 4VPTRIM 1:1. One common conclusion for the studied copolymers is that the degradation starts at a higher temperature than for pure poly(TRIM). The presence of $4 \mathrm{VP}$ improves the thermal stability of microspheres in nonoxidative atmosphere. Nevertheless, this improvement is dependent on the 4VP amount in the copolymer structure, 
Fig. 7 MS profile of the gaseous products emitted from 4VP to TRIM 1:1 in inert conditions

Fig. 8 MS profiles of the main gaseous products evolved during thermal degradation of 4VP-TRIM 1:1 in inert conditions
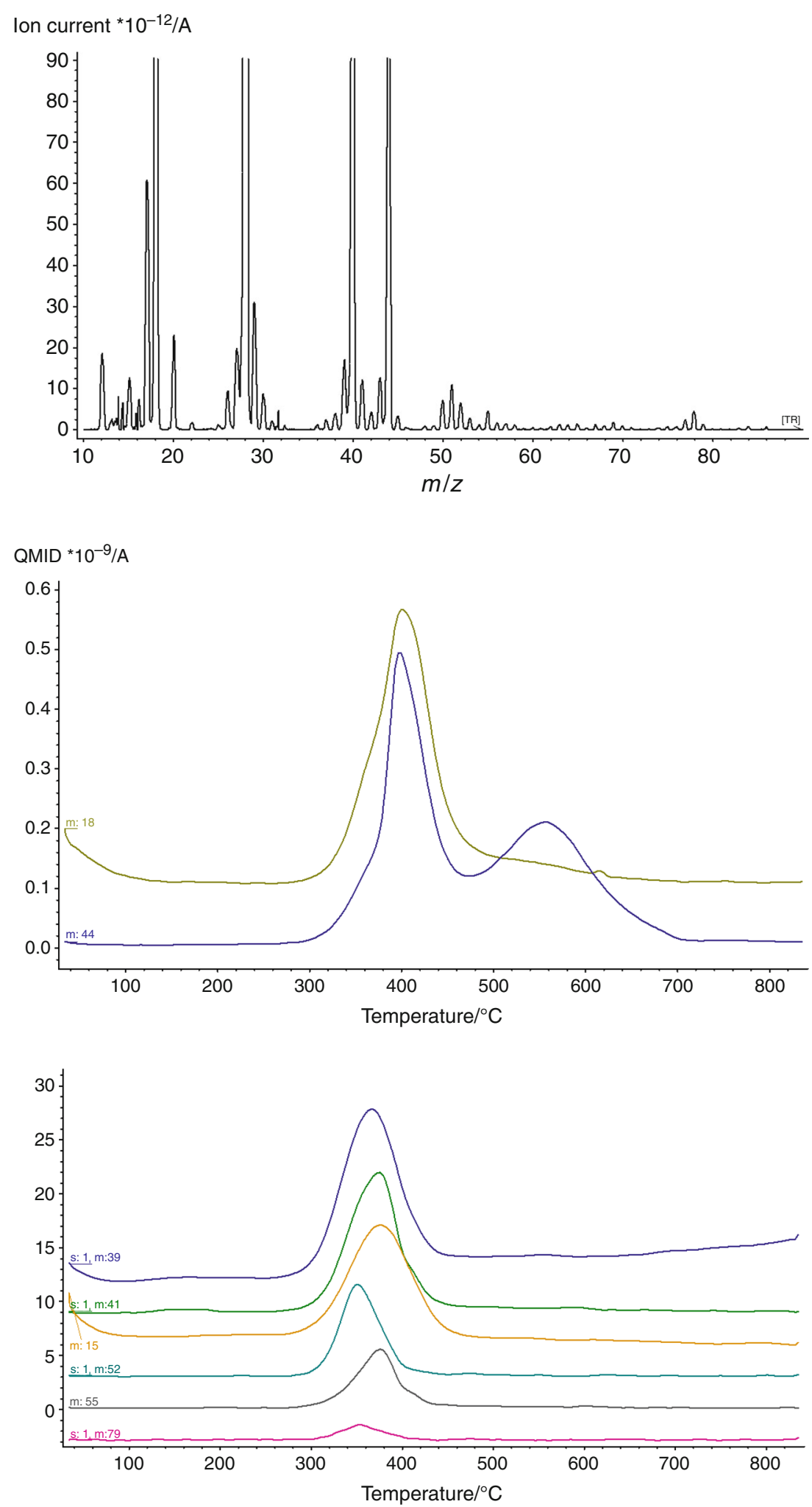

and with the increase in the molar ratio of 4VP:TRIM to $2: 1$, a slight decline in the value of $T_{5 \%}$ is visible. These results are in accordance with the measured DSC data. The second heating DSC curves for all materials in helium are presented in Fig. 5. The analysis was carried out to show that post-crosslinking exothermic processes in microspheres took place at about $180{ }^{\circ} \mathrm{C}$ [6]. Thus, it was confirmed that unreacted methacrylate groups are present in the structure of the prepared microspheres. Thermal destruction of 4VP-TRIM materials started at about 
$270{ }^{\circ} \mathrm{C}$, whereas poly(TRIM) microspheres decomposed at ca $250{ }^{\circ} \mathrm{C}$. It is clearly visible that the first endothermic peaks with $T_{\max }$ at $380{ }^{\circ} \mathrm{C}$ in 4VP-TRIM DSC curves derived from 4 -vinylpyridine units. The second endothermic peaks with $T_{\max }$ at $450{ }^{\circ} \mathrm{C}$ are observed for $4 \mathrm{VP}-$ TRIM and poly(TRIM) materials and are connected with their final decomposition.

Figure 6 presents the three-dimensional diagram of infrared absorption of the evolved gases versus wave number and temperature, and the decomposition rate selected at the maxima (corresponding to $T_{\max 1}$ and $T_{\max 3}$ ) in the FTIR spectra of the evolved gaseous degradation products of 4VP-TRIM 1:1 material. As can be seen, the main decomposition products of 4VP-TRIM microspheres are water (bands in the region of 3,700-3,600 and $1,600-1,400 \mathrm{~cm}^{-1}$ ) and carbon dioxide (peaks at 2357, 2311 and $670 \mathrm{~cm}^{-1}$ ) $[18,19]$. However, in the first emission spectrum weak absorption peaks at $3083,1595,1150$, and $718 \mathrm{~cm}^{-1}$ are visible and they are connected with the emission of pyridine as the main product of thermal decomposition of $4 \mathrm{VP}$ units [17]. It is very likely that the evolution of pyridine took place by the scission mechanism [20]. Moreover, in the first emission spectrum, we can see the weak absorption peak at $1,736 \mathrm{~cm}^{-1}$ characteristic for the $\mathrm{C}=\mathrm{O}$ vibration and also the signal at $3,260 \mathrm{~cm}^{-1}$ (stretching vibration of $-\mathrm{OH}$ group) probably from carboxylic group generated during hydrolysis [21-23]. It can suggest that evolved pyridine accelerates hydrolysis of ester bonds derived from TRIM units. Beside this, the signals for the stretching vibrations of $\mathrm{C}-\mathrm{H}$ in methylene and methyl groups at $2,895-2,977 \mathrm{~cm}^{-1}$ from aliphatic fragments are observed. In the second emission spectrum, peak assignment to carbon dioxide and water is mainly detected. QMS results are convergent with FTIR data. In Fig. 7, the MS spectrum of evolved gases in the maximum of total ion current (corresponding to $T_{1 \max }$ ) is presented, whereas the MS profiles of extracted main ions are shown in Fig. 8. The maximum evolution of pyridine $(\mathrm{m} / \mathrm{z}=79$, $52,39,26)$ is suited at temperature about $50{ }^{\circ} \mathrm{C}$ lower than carbon monoxide $(\mathrm{m} / \mathrm{z}=12,28)$, carbon dioxide $(\mathrm{m} /$ $z=44)$, and water $(m / z=18,17)$. These are the gaseous products of the decarboxylation of the evolved carboxylic compounds. In the MS spectrum in the region corresponding to $\mathrm{T}_{3 \max }$, peaks mainly attributing to carbon dioxide, carbon monoxide, water, and gaseous aliphatic species, especially ethylene $(\mathrm{m} / z=27,28,30)$ are present, and they are connected with the final decomposition of the copolymer [24].

In oxidative conditions, the results are quite different. In Fig. 9, the TG and DTG curves are presented and the DTG peak maxima are listed in Table 1. As can be seen, all 4VP-TRIM materials decompose in two steps with almost the same course, independently of the $4 \mathrm{VP}$ amount in

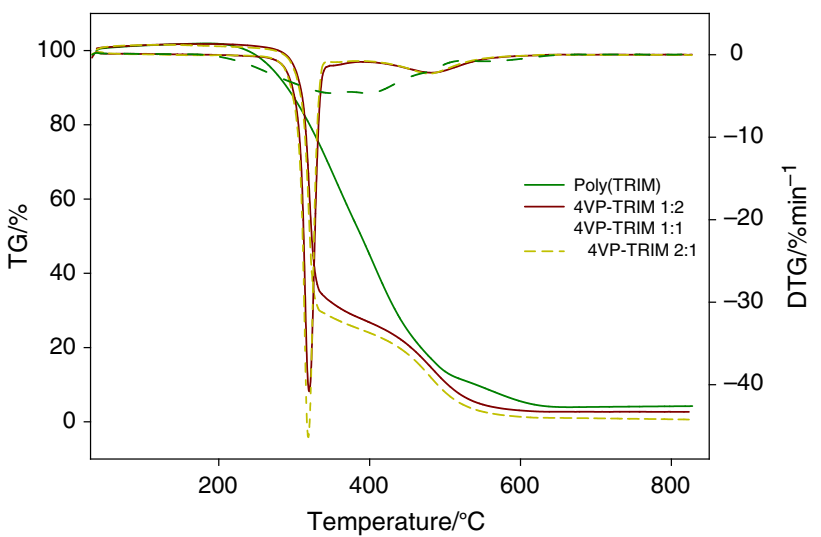

Fig. 9 TG and corresponding DTG curves for poly(TRIM) and 4VPTRIM microspheres obtained in air atmosphere

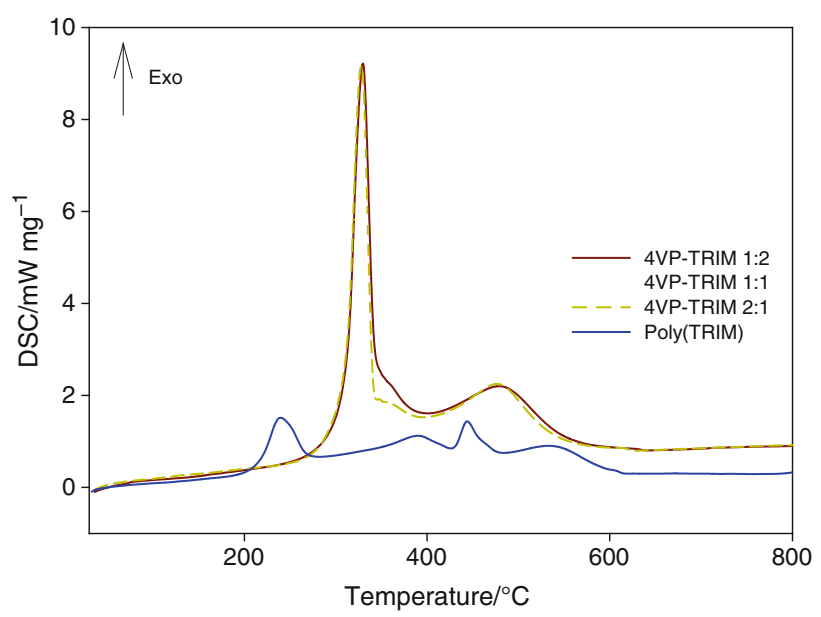

Fig. 10 DSC curves for 4VP-TRIM microspheres obtained in air atmosphere

copolymer network. The degradation processes ran through only two steps. It started at about $300{ }^{\circ} \mathrm{C}$ with a maximum at about $320^{\circ} \mathrm{C}$. The second step took place at about $480{ }^{\circ} \mathrm{C}$. For comparison, the TG curve for poly(TRIM) is also presented in Fig. 9. This polymer underwent a multistep thermal decomposition occurring in three main visible processes observed at 364,410 , and $560{ }^{\circ} \mathrm{C}$. Moreover, the poly(TRIM) $T_{50 \%}$ (where $T_{50 \%}$ is the temperature at which a $50 \%$ mass loss is measured) and 4VP-TRIM 1:1 $T_{50 \%}$ were determined to be 376 and $321{ }^{\circ} \mathrm{C}$, respectively, which indicates the poly(TRIM)'s slower thermal decomposition. In addition, the DSC curves presented in Fig. 10 also show two exothermic peaks corresponding to the mass loss displayed by the TG curves for the 4VP-TRIM materials. The first, exothermic peak starts from ca $290{ }^{\circ} \mathrm{C}$ with a maximum temperature at $330{ }^{\circ} \mathrm{C}$. It is directly connected with the hydrolysis and oxidation processes. It is known that the pyridine ring is a catalyst for hydrolysis of ester bonds, and it can, therefore, be assumed that the pyridine ring exhibits 
(a)

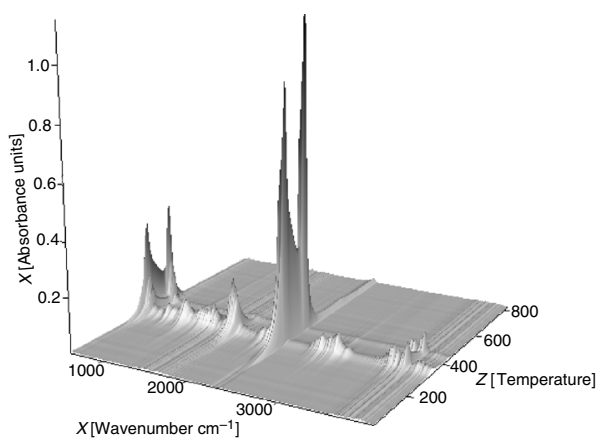

(b)

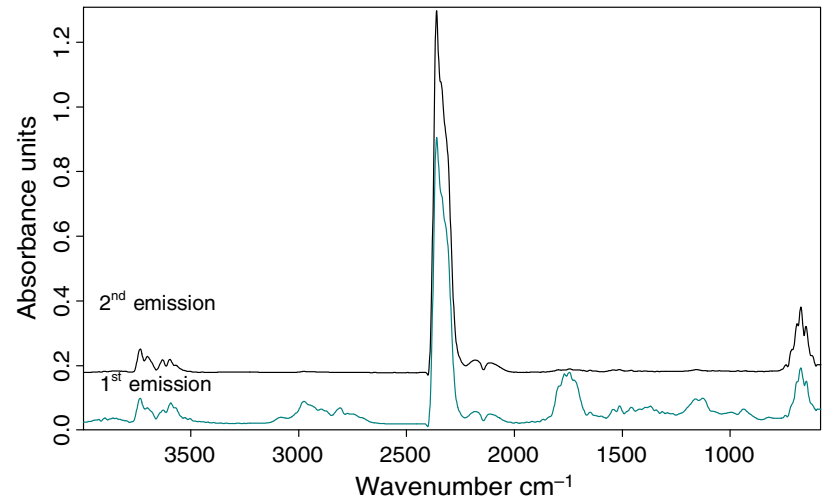

Fig. 11 a 3D FTIR absorption of evolved gases for 4VP-TRIM 1:1 obtained in oxidative atmosphere. b FTIR spectra of gases evolved from 4VP to TRIM 1:1 at the maxima of decomposition

a high catalytic activity, even at low concentration in 4VPTRIM 1:2 material. The second exothermic peak position is in agreement with the position of the decomposition peak on the DTG curve and is observed at temperatures higher than $460{ }^{\circ} \mathrm{C}$. It is probably the result of the oxidation process of the residue formed in the first degradation step.

Additional information about the degradation of the studied materials was also obtained from the analysis of gases evolved during heating. The 3D FTIR spectra and the rate of the decomposition selected at the maxima (corresponding to $T_{\max 1}$ and $T_{\max 3}$ ) in the FTIR spectra of the evolved gaseous degradation products of 4VP-TRIM 1:1 are shown in Fig. 11. As can be seen, the main products of the decomposition of 4VP-TRIM microspheres in oxidative conditions are water (bands in the region of 3,700-3,600 and $1,600-1,400 \mathrm{~cm}^{-1}$ ) and carbon dioxide (peaks at 2357, 2311, and $670 \mathrm{~cm}^{-1}$ ). In addition, weak bands at 2,104 and 2,180 $\mathrm{cm}^{-1}$ are observed. This indicates the formation of carbon oxide during the decomposition. Moreover, in the first stage of the process peaks in the region of about $2,900-2,800 \mathrm{~cm}^{-1}$ is visible and they are related to aliphatic fragments. The peak at $1,740 \mathrm{~cm}^{-1}$ suggests that carboxylic gaseous compounds were generated. As in inert atmosphere, also in oxidative conditions an evolution of pyridine is visible on the FTIR spectrum (absorption peaks at $3083,1595,1150$, and $718 \mathrm{~cm}^{-1}$ ) [18]. Furthermore, the presence of additional bands at $824 \mathrm{~cm}^{-1}$ (deformation out of the plane vibrations of $=\mathrm{C}-\mathrm{H}$ ) and $1641 \mathrm{~cm}^{-1}$ (stretching vibrations of $\mathrm{C}=\mathrm{C}$ ) may indicate the formation of alkene fragments during oxidation [20]. The results from FTIR analysis are confirmed also by QMS measurements of the evolved gases. In Fig. 12, the MS spectrum of the evolved gases in the maximum of total ion current (corresponding to $T_{1 \max }$ ) is presented, whereas MS profiles of extracted main ions are shown in Fig. 13. As can be seen, the maximum evolution of pyridine $(\mathrm{m} / \mathrm{z}=$ $79,52,39,26)$ takes place at the same temperature as the first maximum evolution of carbon dioxide and water. Thus, it can be concluded that the degradation processes of hydrolysis and oxidation have run in parallel. Carbon monoxide $(\mathrm{m} / \mathrm{z}=12,28)$, carbon dioxide $(\mathrm{m} / \mathrm{z}=44)$, and water $(m / z=18,17)$ are the main gaseous products of $4 \mathrm{VP}$ TRIM decomposition in oxidative conditions. However,
Fig. 12 MS profile of the gaseous products emitted from 4VP to TRIM 1:1 in oxidative conditions

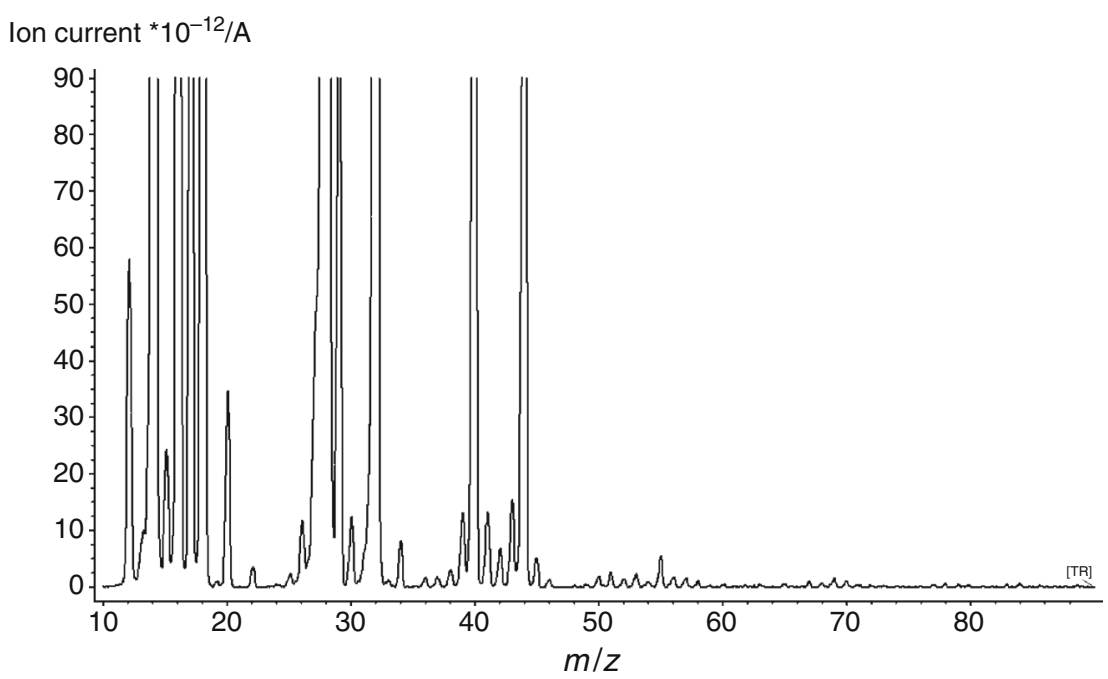


Fig. 13 MS profiles of the main gaseous products evolved during thermal degradation of 4VP-TRIM 1:1 in oxidative conditions
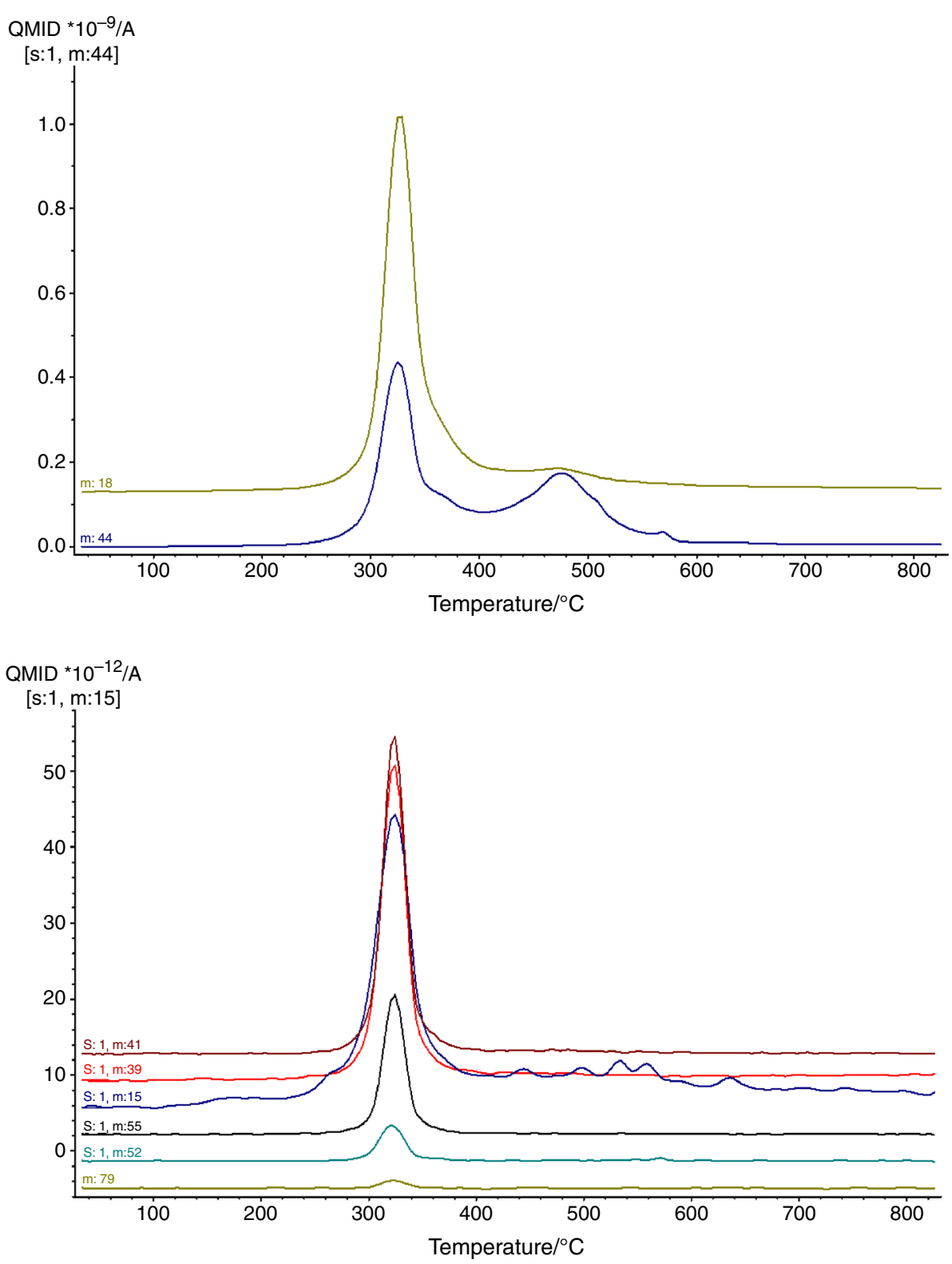

gaseous organic species containing aliphatic fragments, carbonyl groups and in addition pyridine, were also evolved.

\section{Conclusions}

The thermal behavior of new 4VP-TRIM microspheres prepared by seed polymerization was investigated by means of the DSC and STA-FTIR-QMS methods. FTIR and $\mathrm{CHN}$ results confirm that $4 \mathrm{VP}$ was successfully incorporated in copolymer networks. The synthesized materials are characterized by high thermal stability in both inert and oxidative atmospheres. Their initial decomposition temperature is about $300{ }^{\circ} \mathrm{C}$, depending on the degree of material crosslinking. It was found that the presence of 4VP monomer units in the copolymeric network with TRIM monomer units improved the thermal stability of such materials. The FTIR and QMS analyses of the gaseous species emitted during the decomposition processes have shown that pyridine, as the main degradation product of 4VP units, acts as a catalyst of the hydrolysis of ester bonds existing in the 4VP-TRIM copolymer network. Therefore, carboxylic group absorption peaks in the FTIR spectra were present. In both inert and oxidative atmospheres as the main decomposition gases $\mathrm{CO}_{2}, \mathrm{H}_{2} \mathrm{O}$, and $\mathrm{CO}$ were observed. Moreover, gaseous organic species containing aliphatic fragments, carbonyl groups and in addition pyridine, were also detected. From the chromatographic 
standpoint, the thermal stability of the prepared microspheres is sufficient to use them as column packings in chromatographic experiments carried out in higher temperatures.

Acknowledgements This research was supported by the National Science Centre of Poland (Grant No NN204354140). The research was carried out with the equipment purchased thanks to the financial support of the Operational Programme Development of Eastern Poland 2007-2013.

Open Access This article is distributed under the terms of the Creative Commons Attribution License which permits any use, distribution, and reproduction in any medium, provided the original author(s) and the source are credited.

\section{References}

1. Podkościelna B, Bartnicki A, Gawdzik B. New crosslinked hydrogels derivatives of 2-hydroxyethyl methacrylate: synthesis, modifications and properties. Express Polym Lett. 2012;6:759-71.

2. Prasath RA, Gokmen MT, Espeel P, Du Prez FE. Thiol-ene and thiol-yne chemistry in microfluidics: a straightforward method towards macroporous and nonporous functional polymer beads. Polym Chem. 2010;1:685-92.

3. Ferreira A, Bigan M, Blondeau D. Optimization of a polymeric HPLC phase: poly(glycidyl methacrylate-co-ethylene dimethacrylate): influence of the polymerization conditions on the pore structure of macroporous beads. React Funct Polym. 2003;56:123-36.

4. Grochowicz M, Bartnicki A, Gawdzik B. Synthesis of a new tetrafunctional monomer, 1,4-di(2-hydroxy-3-methacryloyloxypropoxy)phenol, and its copolymerization. J Appl Polym Sci. 2008;107:3718-26.

5. Grochowicz M, Gawdzik B. Preparation and characterization of porous crosslinked microspheres of new aromatic methacrylates. J Porous Mater. 2013;20:339-49.

6. Grochowicz M, Gawdzik B. Permanently porous copolymeric microspheres based on aromatic methacrylates. React Funct Polym. 2011;71:625-33.

7. Podkościelna B. Synthesis, modification and porous properties of new glycidyl methacrylate copolymers. J Appl Polym Sci. 2011;120:3020-6.

8. Kip C, Maras B, Evirgen O, Tuncel A. A new type of monodisperse porous, hydrophilic microspheres with reactive chloroalkyl functionality: synthesis and derivatization properties. Colloid Polym Sci. 2014;292:219-28.
9. Galia M, Svec F, Frechet JMJ. Monodisperse polymer beads as packing material for high-performance liquid chromatography: effect of divinylbenzene content on the porous and chromatographic properties of poly(styrene-co-divinylbenzene) beads prepared in presence of linear polystyrene as a porogen. J Polym Sci. 1994;32:2169-75.

10. Caglayan B, Unsal E, Camli ST, Tuncel M, Tuncel A. Monodisperse porous poly(vinyl acetate-codivinylbenzene) particles by single-stage seeded polymerization: a packing material for reversed phase HPLC. J Sep Sci. 2006;29:936-44.

11. Jiang S, Sudol ED, Dimonie VL, El-Aasser MS. Seeding as a means of controlling particle size in dispersion polymerization. J Appl Polym Sci. 2008;108:4096-107.

12. Chambree D, Iditoiu C, Segal E, Cesaro A. The study of nonisothermal degradation of acrylic ion-exchange resins. J Therm Anal Calorim. 2005;82:803-11.

13. Zhang J, Qian H. Thermal behavior of typical weak basic ion exchange resin. J Therm Anal Calorim. 2014;115:875-80.

14. Grochowicz M, Gawdzik B, Jaćkowska M, Buszewski B. Investigation of the thermal behavior of new silica-polymer anion exchangers. J Therm Anal Calorim. 2013;112:885-91.

15. Maciejewska M, Osypiuk-Tomasik J. TG/DSC studies of modified 1-vinyl-2-pyrrolidone-divinylbenzene copolymers. J Therm Anal Calorim. 2013;113:343-50.

16. Azhari SJ, Dish MA. Thermal degradation and stability of poly(4vinylpyridine) homopolymer and copolymers of 4-vinylpyridine with methyl acrylate. Polym Degrad Stabil. 1998;60:253-6.

17. Filipovic J, Petrovic-Dakov D, Katsikas L, Bozic B. The thermal degradation of poly(dimethylitaconate-co-4-vinylpyridine). J Therm Anal Calorim. 2000;62:251-6.

18. NIST chemistry webbook standard reference database number 69 , 2011, http://webbook.nist.gov/chemistry. Accessed 4 May 2014.

19. Grochowicz M, Gawdzik B, Jaćkowska M, Buszewski B. Thermal characterization of polymeric anion exchangers with a dendrimeric structure. J Therm Anal Calorim. 2013;114:955-61.

20. Moldoveanu S, Analytical pyrolysis of synthetic organic polymers, vol 25 (Techniques and instrumentation in analytical chemistry). 1st ed. New York: Elsevier Science; 2005.

21. Zhang T, Howell BA, Smith PB. Thermal degradation of trimethylolpropane/adipic acid hyperbranched poly(ester)s. J Therm Anal Calorim. 2014;116:1369-78.

22. Worzakowska M, Ścigalski P. Synthesis and thermal behavior of linear neryl diesters in inert and oxidative atmosphere. J Therm Anal Calorim. 2014;115:783-92.

23. Cai GM, Yu WD. Study on the thermal degradation of high performance fibers by TG/FTIR and Py-GC/MS. J Therm Anal Calorim. 2011;104:757-63.

24. Worzakowska M. Synthesis, characterization, and thermal properties of new flavour compounds. J Therm Anal Calorim. 2014;116:727-36. 